University of South Florida

DIGITAL COMMONS

Digital Commons @ University of

@ UNIVERSITY OF SOUTH FLORIDA

South Florida

School of Geosciences Faculty and Staff

Publications

School of Geosciences

$11-2009$

\title{
Stability of the Rotation Axis in High-Resolution Mantle circulation Models: Weak Polar Wander despite Strong core Heating
}

\author{
K. Schaber \\ Ludwig-Maximilians-Universität München
}

H. -P. Bunge

Ludwig-Maximilians-Universität München

B. S. A. Schuberth

Ludwig-Maximilians-Universität München

Rocco Malservisi

Ludwig-Maximilians-Universität, rocco@usf.edu

A. Horbach

Ludwig-Maximilians-Universität München

Follow this and additional works at: https://digitalcommons.usf.edu/geo_facpub

Part of the Earth Sciences Commons

\section{Scholar Commons Citation}

Schaber, K.; Bunge, H. -P.; Schuberth, B. S. A.; Malservisi, Rocco; and Horbach, A., "Stability of the Rotation Axis in High-Resolution Mantle circulation Models: Weak Polar Wander despite Strong core Heating" (2009). School of Geosciences Faculty and Staff Publications. 2205.

https://digitalcommons.usf.edu/geo_facpub/2205

This Article is brought to you for free and open access by the School of Geosciences at Digital Commons @ University of South Florida. It has been accepted for inclusion in School of Geosciences Faculty and Staff Publications by an authorized administrator of Digital Commons @ University of South Florida. For more information, please contact digitalcommons@usf.edu. 


\title{
Stability of the rotation axis in high-resolution mantle circulation models: Weak polar wander despite strong core heating
}

\author{
K. Schaber, H.-P. Bunge, B. S. A. Schuberth, R. Malservisi, and A. Horbach \\ Geophysics Section, Department of Earth and Environmental Sciences, Ludwig-Maximilians-Universität München, \\ Theresienstrasse 41, D-80333 Munich, Germany (mail@bernhard-schuberth.de)
}

[1] Growing evidence points to a substantial heat flow across the core-mantle boundary (CMB), but the rotational stability of strongly bottom heated mantle flow with prominent upwelling plumes is poorly known. Here we calculate polar motion for the past $100 \mathrm{Myr}$ induced in a new class of isochemical highresolution mantle circulation models (MCMs) with Earth-like convective vigor and up to $12 \mathrm{TW}$ core heat flux. Our MCMs include internal heating and a simple three-layer viscosity profile associated with the lithosphere $\left(10^{23} \mathrm{~Pa} \mathrm{~s}\right)$ and the upper $\left(10^{21} \mathrm{~Pa} \mathrm{~s}\right)$ and the lower mantle $\left(10^{23} \mathrm{~Pa} \mathrm{~s}\right)$, separated at 100 and $650 \mathrm{~km}$ depth, respectively. A published mantle mineralogy model in the pyrolite composition, consistent with our assumption of whole mantle flow, allows us to relate thermal to density variations in a thermodynamically self-consistent way. All models yield modest polar motion on the order of $0.5^{\circ} \mathrm{Myr}^{-1}$ or less, in accordance with paleomagnetic data and agreeing with a number of studies that demonstrate the stabilizing effect of the rotational bulge. Although a substantially reduced lower mantle viscosity would increase this rate, the good agreement between MCM and seismic mantle heterogeneity lends independent support for our viscosity profile, as otherwise, slabs in the MCM would rapidly sink to depth levels where they are tomographically not observed. In general, there is good agreement between the long-wavelength geoids predicted from our MCMs and recent satellite derived models of Earth's geoid (correlation coefficient of around 0.4), but noticeable differences at intermediate wavelengths, for example, in the western Pacific and in Africa, suggest the use of gravity data to distinguish between competing plate reconstruction models.

Components: 9507 words, 8 figures, 1 table.

Keywords: true polar wander; geoid; mantle circulation models; density anomalies; strong core heating; viscosity.

Index Terms: 1219 Geodesy and Gravity: Gravity anomalies and Earth structure (0920, 7205, 7240); 8121 Tectonophysics: Dynamics: convection currents, and mantle plumes; 8162 Tectonophysics: Rheology: mantle (8033).

Received 6 April 2009; Revised 20 July 2009; Accepted 3 September 2009; Published 17 November 2009.

Schaber, K., H.-P. Bunge, B. S. A. Schuberth, R. Malservisi, and A. Horbach (2009), Stability of the rotation axis in highresolution mantle circulation models: Weak polar wander despite strong core heating, Geochem. Geophys. Geosyst., 10, Q11W04, doi:10.1029/2009GC002541.

Theme: Plate Reconstructions, Mantle Convection, and Tomography Models: A Complementary Vision of Earth's Interior

Guest Editors: D. Muller, S. Quere, and T. Torsvik 


\section{Introduction}

[2] True polar wander (TPW), the coherent motion of the Earth's surface with respect to its rotation axis, is most likely controlled by redistribution of deep seated mass anomalies due to vigorous convection inside the Earth's mantle. Paleomagnetic evidence suggests that this motion has been small, not exceeding more than $10-15^{\circ}$ of latitudinal variation during the past $100 \mathrm{Myr}$ [Besse and Courtillot, 1991, 2002; Tarduno and Smirnov, 2001]. Thus, the rate of TPW has been on average only about $0.1^{\circ}$ to $0.2^{\circ} \mathrm{Myr}^{-1}$.

[3] The apparent stability of the Earth's rotation axis is at odds with results from isoviscous whole mantle convection models, which predict much faster TPW rates on the order of $1^{\circ}$ to $10^{\circ} \mathrm{Myr}^{-1}$ [Richards et al., 1999]. The rate slows to about $0.5^{\circ} \mathrm{Myr}^{-1}$ for mantle convection with a high-viscosity lower mantle due to the large-scale planform induced by depth-dependent viscosity [Bunge and Richards, 1996; Bunge et al., 1996]. Thus, the most plausible explanation for the Earth's small TPW rests with the great stability of the upper thermal boundary layer of the mantle, the lithosphere, and the gradual movement of its major subduction systems. Support for this comes in the form of analytic models, where subduction histories or advected mass anomalies inferred from seismic tomography are used to estimate the time evolution of mantle heterogeneity for the Cenozoic and Mesozoic [Richards et al., 1997; Steinberger and O'Connell, 1997].

[4] It may seem obvious to consider mass anomalies from the upper thermal boundary layer in the excitation of TPW. More interesting is the fact that geodynamicists have long assumed the lower thermal boundary layer at the core-mantle boundary to be of less importance, an assumption that stems from a classic argument involving the modest dynamic topography observed over hot spots. This has been taken to suggest a minor core heat flux contribution of about $5 \%(\sim 1.5 \mathrm{TW})$ to the global mantle heat budget [Sleep, 1990; Davies, 1988], implying that hot thermal upwellings in the deep mantle play a secondary role in the dynamics of the Earth, although some geodynamicists have argued early on that one must account for strong upwellings to predict an excess ellipticity of the coremantle boundary (CMB) that is consistent with geodetic observations [Forte et al., 1995].

[5] A number of geodynamic studies have called this assumption into question. They favor a high core heat flux in order to overcome problems of insufficient internal mantle heat sources [Kellogg et $a l ., 1999]$, or to satisfy constraints on the power requirement of the geodynamo [Glatzmaier and Roberts, 1995; Kuang and Bloxham, 1997] and the thermal history of the core [Buffett, 2002; Nimmo et al., 2004; Costin and Butler, 2006]. The notion of strong core heating is further supported by novel tomographic imaging techniques, which reveal a variety of lower mantle plumes [Montelli et al., 2004].

[6] A key argument for high core heat flux involves the nonadiabatic nature of the mantle geotherm away from thermal boundary layers [Jeanloz and Morris, 1987], which arises from internal radioactive heat production and secular cooling of the mantle. Several studies have concluded that the mantle geotherm departs by as much as $500 \mathrm{~K}$ from the adiabat [Bunge et al., 2001; Monnereau and Yuen, 2002; Sleep, 2003]. The net effect of mantle nonadiabaticity is a strong thermal gradient and a correspondingly high heat flux across the CMB, as large as $15-30 \%(5-10 \mathrm{TW})$ of the total mantle heat loss [Bunge, 2005; Mittelstaedt and Tackley, 2006; Leng and Zhong, 2008; Lay et al., 2008]. Thus bottom heating and buoyant mass anomalies from a lower thermal boundary layer (i.e., plumes) may affect the mantle general circulation and the rotational stability of the Earth more prominently than what is commonly assumed.

[7] Modeling the mantle general circulation has made great progress in the last decade. Based on the conservation laws for mass, momentum, and energy, geodynamicists have constructed so-called mantle circulation models to explore the structure of mantle heterogeneity and its temporal evolution in realistic 3-D spherical geometry [Bunge et al., 1998, 2002; McNamara and Zhong, 2005]. MCMs involve conductive and advective heat transport and account explicitly for density heterogeneities originating from the lower thermal boundary layer in addition to density anomalies associated with past subduction [Ricard et al., 1993a].

[8] Rapid growth of computational resources allows exploring MCMs at very high numerical resolution. In fact, models with more than 80 million finite elements and a grid point resolution of less than $30 \mathrm{~km}$ globally are feasible now [Oeser et al., 2006]. With this resolution, highly time-dependent mantle circulation can be studied at Earth-like convective vigor with a thermal Rayleigh number of $10^{9}$ based on internal heating. Put differently, a characteristic thermal boundary layer thickness on the order of $100 \mathrm{~km}$ in the mantle can be resolved, comparable to that represented by the oceanic lithosphere. 
[9] A key motivation for high numerical resolution in MCMs is the ability to model lateral and radial temperature variations comparable in magnitude to those expected in the Earth. This is essential to exploit recent progress in high-pressure petrology, which makes it possible to build thermodynami-
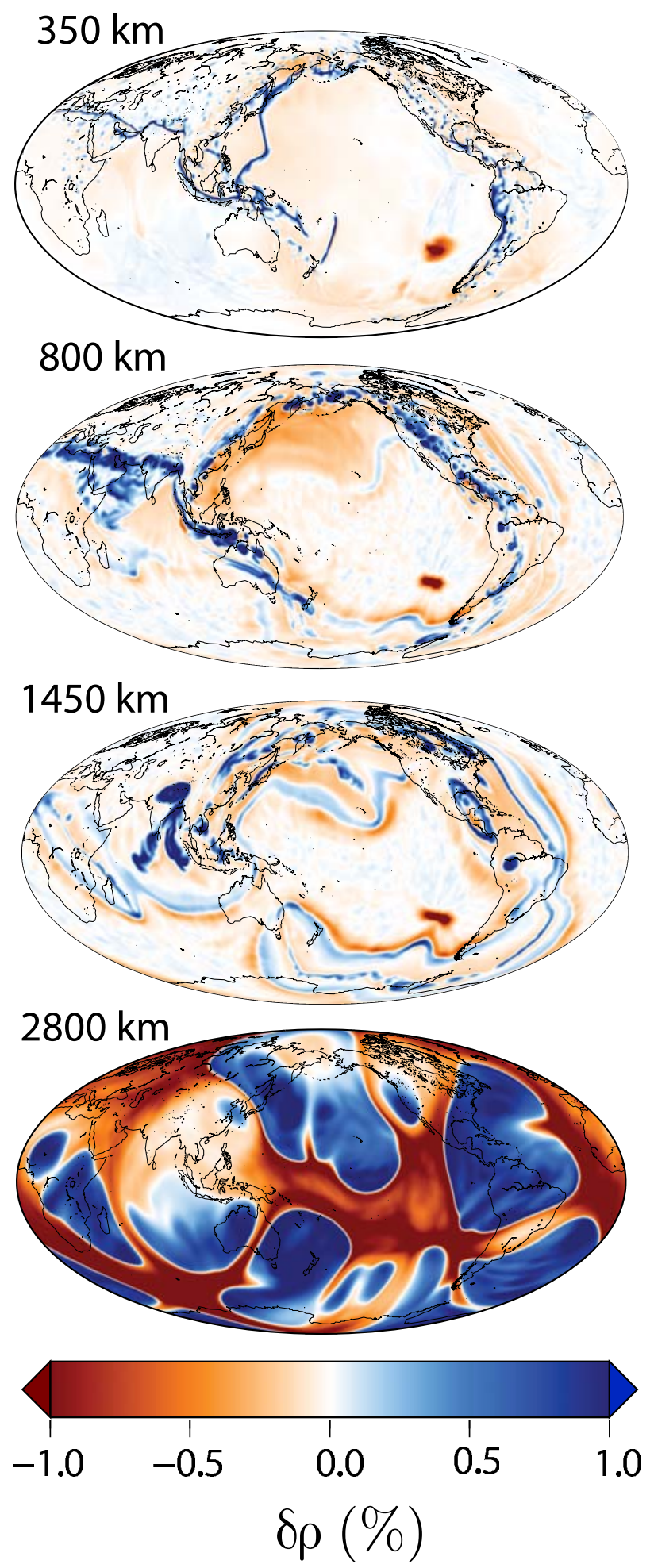

cally self-consistent mantle mineralogy models [Stixrude and Lithgow-Bertelloni, 2007; Piazzoni et al., 2007], and to convert every P,T,x (pressure, temperature, composition) condition of the mantle to a stable phase assembly and its corresponding physical properties such as density.

[10] The density structure predicted in this way from a high-resolution MCM with substantial core heating ( $35 \%$ of the surface heat loss) is shown in Figure 1 (see Figure 1 caption and Table 1 for modeling parameters). To keep things simple, a three-layer viscosity profile is assumed in agreement with geoid [e.g., Hager and Richards, 1989] and postglacial rebound studies [e.g., Mitrovica, 1996]. The choice of pyrolite as compositional model [Ringwood, 1975; Irifune, 1987] to map thermal into density variations is consistent with the implicit assumption of whole mantle flow. A detailed analysis of the thermal structure of this model and its corresponding elastic heterogeneity is given by Schuberth et al. [2009a, 2009b].

[11] In this paper, we explore the effects of substantial core heat flux on the rotational stability of

Figure 1. Depth slices through the present-day density distribution of the mantle circulation model M3 with $35 \%$ core heating $(\mathrm{CH})$ corresponding to about $12 \mathrm{TW}$ of core heat flux. In the upper mantle at $350 \mathrm{~km}$ depth, slabs located in areas of present-day subduction control the density structure. At $800 \mathrm{~km}$ depth, the position of the prominent cold dense downwellings have changed according to the plate configuration of earlier stages of subduction, for example, all around the Pacific. Cold material associated with subduction of the Farallon plate lies east of North America's West Coast in this depth, and remnants of the Tethys Ocean can be found as a distinct dense feature beneath Africa, Arabia, and India. A hot low-density anomaly is located in the southeast Pacific. There is little overall change in the midmantle, at $1450 \mathrm{~km}$ depth, except for the location of downwellings. Here the Farallon slab lies east of North America, and remnants of subduction exist under Central America. The feature with the largest thermal amplitude is a number of downwelling slabs corresponding to the collision of India and Eurasia. Cold material exists also in the North Pacific and belongs to the Kula plate which, in the reconstruction model of Lithgow-Bertelloni and Richards [1998], converged with North America at about 50-70 Ma. In the lowermost mantle at $2800 \mathrm{~km}$ depth, hot upwellings give rise to large lateral density variations, reaching maximum values of up to $\pm 1 \%$. A detailed analysis of the underlying thermal structure and its corresponding elastic heterogeneity shows that this model is compatible with tomography for a number of quantitative measures [Schuberth et al., 2009a, 2009b]. 
Table 1. Physical Parameters and Values Employed in the Simulations of Mantle Circulation ${ }^{\mathrm{a}}$

\begin{tabular}{lll}
\hline \multicolumn{1}{c}{ Parameter } & \multicolumn{1}{c}{ Value } & \multicolumn{1}{c}{ Unit } \\
\hline Outer shell radius & 6370 & $\mathrm{~km}$ \\
Inner shell radius & 3480 & $\mathrm{~km}$ \\
$T_{\text {Surface }}$ & 300 & $\mathrm{~K}$ \\
$\eta_{\text {ref }}$ (reference viscosity) & $1.0 \times 10^{21}$ & $\mathrm{~Pa} \mathrm{~s}$ \\
Thermal conductivity $k$ & 3.0 & $\mathrm{~W} \mathrm{~m}^{-1} \mathrm{~K}^{-1}$ \\
Thermal expansivity $\alpha$ (surface) & $4.011 \times 10^{-5}$ & $\mathrm{~K}^{-1}$ \\
Thermal expansivity $\alpha(\mathrm{CMB})$ & $1.256 \times 10^{-5}$ & $\mathrm{~K}^{-1}$ \\
Internal heating rate $Q_{\text {int }}$ & $6.0 \times 10^{-12}$ & $\mathrm{~W} \mathrm{~kg}^{-1}$ \\
Heat capacity & $1.134 \times 10^{3}$ & $\mathrm{~J} \mathrm{~kg}^{-1} \mathrm{~K}^{-1}$ \\
$R a_{H}$ (based on $\eta$ upper mantle) & $\simeq 10^{9}$ & \\
\hline
\end{tabular}

\footnotetext{
${ }^{\mathrm{a}}$ Values in Table 1 were kept constant in all three mantle circulation
} models $\mathrm{M} 1-\mathrm{M} 3$.

MCMs, testing the hypothesis that strongly bottom heated mantle flow is compatible with the record of Mesozoic and Cenozoic polar motion. Geodynamic mantle heterogeneity is computed from highresolution MCMs as in the work by Schuberth et $a l$. [2009b] and geoids and TPW are then calculated analytically from the density anomalies, taking the same viscosity profile assumed in the MCMs. This assures consistency between modeled mantle heterogeneity and its geoid and TPW response.

[12] Aside from geodynamic parameters such as viscosity stratification or $\mathrm{CMB}$ temperature, the density structure of the MCMs is directly affected by past plate motion models. Such models are assimilated into MCMs to organize the temporal evolution of the flow and to direct the location of major downwellings. The plate motion models are limited to the past $100-150 \mathrm{Myr}$, the age of the oldest ocean floor. A widely adopted model, which spans the past 120 Myr by building on the Cenozoic reconstructions of Gordon and Jurdy [1986], was introduced by Lithgow-Bertelloni and Richards [1998]. However, alternative plate reconstructions have been proposed [Hall, 2002; Quere et al., 2007; Müller et al., 2008]. These models suggest different plate geometries and therefore imply substantial uncertainties in the modeled mantle density structure and its temporal evolution. These uncertainties must be considered in addition to the ones inherent in modeling parameters and initial conditions when assessing predictions from mantle circulation modeling for the evolution of Mesozoic and Cenozoic mantle flow.

[13] Starting from a short description of the computational methods and parameters employed in the MCMs, we briefly review the theory and analytic methods involved in geoid and TPW computation. We then compare our results with observations and find an excellent agreement between synthetic and satellite derived geoids at long wavelengths (correlation $>40 \%$ ). This analysis furthermore suggests the use of gravity data to distinguish explicitly between competing plate reconstructions. Importantly, we find that the predicted rate of polar motion in MCMs with strong core heating remains within the paleomagnetic bounds. This indicates that the Earth's TPW signal can be reconciled with isochemical whole mantle circulation having a strong active upwelling flow component.

\section{Model Setup}

[14] We model the circulation of the mantle using the parallel finite element TERRA code [Bunge and Richards, 1996; Bunge et al., 1997]. Input parameters are summarized in Table 1 and equivalent to Schuberth et al. [2009b]. The code solves for momentum and energy balance of a highly viscous fluid at infinite Prandtl number (no inertial forces) in a spherical shell corresponding to the Earth's mantle. The modeling domain is discretized with a mesh derived from the icosahedron to assure an almost uniform grid spacing at each radial level. A global grid spacing of around $25 \mathrm{~km}$, resulting in $\sim 80$ million finite elements, allows us to model mantle circulation at Earth-like convective vigor, expressed by a thermal Rayleigh number of $10^{9}$ based on internal heating. This is about ten times the value explored in earlier MCMs [Bunge et al., 2002] and yields highly time-dependent flow. The models are implemented on 128 cores of a topical compute cluster dedicated to large-scale geophysical modeling [Oeser et al., 2006].

[15] The rheologic stratification of our MCMs is a simple three-layer viscosity profile. The layers are identified with the lithosphere, the upper mantle and lower mantle, which are separated at 100 and $650 \mathrm{~km}$ depth. The assigned viscosities are $10^{23}, 10^{21}$ and $10^{23} \mathrm{~Pa} \mathrm{~s}$. Mechanical boundary conditions are always free slip at the CMB (the core supports no shear stress), while the surface velocities are specified according to the plate motion history of LithgowBertelloni and Richards [1998]. We follow the philosophy of Bunge et al. [1998, 2002] and approximate the unknown initial condition of midCretaceous mantle heterogeneity by running our models with global plate configurations fixed to the oldest available reconstructions at $120 \mathrm{Ma}$ until they reach a thermal quasi steady state. 
[16] The thermal boundary conditions are constant temperature at the surface $(300 \mathrm{~K})$ and the CMB. In order to clearly isolate the effects of bottom heating, we focus on three MCMs (M1-M3), for which we vary the $\mathrm{CMB}$ temperature in such a way as to produce models with weak or strong core heat flux, while keeping all other model parameters constant (see Table 1). M1 is a standard MCM with mostly internal heating. A modest CMB heat flux of $1.5 \mathrm{TW}$ (around 5\% of the total surface heat flow) is accomplished in this model by setting the CMB temperature to $2900 \mathrm{~K}$. M2 has an intermediate core heat flux of $6 \mathrm{TW}$ (roughly $20 \%$ of the surface heat flow) obtained from a CMB temperature of $3500 \mathrm{~K}$. A rather high core heat flux of $12 \mathrm{TW}$ (around $35 \%$ of the total surface heat flow) results in M3 from setting the temperature at the CMB to a value of $4200 \mathrm{~K}$. M1 and M3 are end-members in terms of core heating with Urey numbers (the ratio of internal heating to total surface heat loss) of 0.95 and 0.65 , respectively, and span a reasonable range of core heat flux values.

[17] Density anomalies for either the present-day or earlier geologic times (in case of TPW calculations) of $\mathrm{M} 1-\mathrm{M} 3$ are obtained from mapping absolute temperatures into the corresponding absolute densities, which are afterward referenced to the mean values in each radial layer. For this conversion, we take advantage of a recently published thermodynamically self-consistent model of mantle mineralogy [Piazzoni et al., 2007]. This model is based on physical measurements (e.g., equation of state by X-ray diffraction, phase equilibria, calorimetric data) of material properties in the CFMAS $\left(\mathrm{CaO}-\mathrm{FeO}-\mathrm{MgO}-\mathrm{Al}_{2} \mathrm{O}_{3}-\mathrm{SiO}_{2}\right)$ system. As noted in section 1, we assume a pyrolite bulk composition consistent with our assumption of whole mantle flow to convert the P,T condition at each model grid point to its corresponding density.

\section{Analysis of Mass Anomalies in the Mantle}

\subsection{Geoids}

[18] The computation of the geoid from the geodynamic density structure is carried out using the classic analytic formalism of geoid kernels [Richards and Hager, 1984; Ricard et al., 1984]. The kernels $K_{l}\left(r^{\prime}\right)$ give the geoid anomaly at the surface in meters for a unit mass anomaly at each depth and degree of spherical harmonics. The sign and shape of the kernels indicate whether contributions to the gravita- tional signal coming from the mass anomaly or the induced deformation of internal and external interfaces (notably the surface and the CMB) prevail. The geoid anomaly $N$ is obtained by a multiplication of the kernel $K_{l}\left(r^{\prime}\right)$ and the density anomaly at each depth $r^{\prime}$ integrated from the CMB, $c$, to the surface, $a$ :

$$
\begin{aligned}
N_{l m} & =\int_{c}^{a} K_{l}\left(r^{\prime}\right) \rho_{0}\left(r^{\prime}\right) \delta \rho_{l m}\left(r^{\prime}\right) d r^{\prime} \\
& \approx \sum_{i=1}^{n} K_{l}\left(r_{i}\right) \rho_{0}\left(r_{i}\right) \delta \rho_{l m}\left(r_{i}\right) \Delta r_{i}
\end{aligned}
$$

where $N_{l m}$ and $\delta \rho_{l m}$ are the expansion coefficients in spherical harmonics of the geoid and the density anomalies, respectively, and $\rho_{0}$ is the reference density in the mantle. For the actual computations, the integral is approximated by a finite sum over the $n=128$ layers of our MCMs, each of thickness $\Delta r_{i}$. In the calculation of the geoid kernels, incompressibility of the mantle is implicitly assumed. We note, however, that compressibility would have only minor effects for the viscosity structure used here [Panasyuk et al., 1996].

[19] Figure 2 shows the kernels for the three-layer viscosity profile used in our MCMs. The kernels are zero at the surface and the CMB, as isostatic adjustment is assumed at these two boundaries, and change sign within the mantle. For spherical harmonic degree two, which is prominent in the Earth's gravity field, the kernel nearly vanishes in the uppermost $100 \mathrm{~km}$, is positive between $80 \mathrm{~km}$ and $1200 \mathrm{~km}$ depth and negative otherwise, so that deeply seated positive mass anomalies in the lower mantle, such as subducted slabs, result in geoid lows, while negative mass anomalies, such as upwelling plumes are associate with geoid highs.

[20] Figure 3 shows the observed geoid and the geoids derived from the density anomalies of M1M3 up to degree and order 20. The observed nonhydrostatic geoid (Figure $3 \mathrm{a}$ ) is obtained from the latest satellite-only gravity model GL04S1 [Förste et al., 2006; Nakiboglu, 1982]. It shows major geoid highs over Africa and the western Pacific, with a great circle band of geoid lows in the intervening regions. Note that the proximity of the African geoid high to the position of the former supercontinent Pangaea has been taken early on to suggest anomalously warm, buoyant mantle in this region due to continental insulation [Anderson, 1982], an inference that is also supported by recent geodynamic modeling [Phillips and Bunge, 2005, 2007; Coltice et al., 2007; Phillips et al., 2009]. 


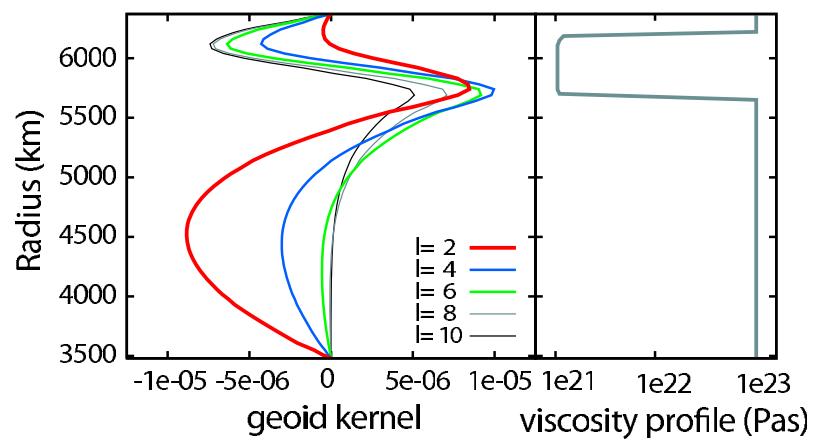

Figure 2. (left) Geoid kernels for different spherical harmonic degrees. (right) The corresponding viscosity structure agrees with geoid [e.g., Hager and Richards, 1989] and postglacial rebound studies [e.g., Mitrovica, 1996]. The kernels give the geoid anomaly at the surface for a unit probing mass anomaly: their shape and sign indicate whether the gravitational signal is dominated by the mass anomaly or by deformation of internal and external interfaces (notably the surface and the CMB). Due to isostatic compensation, all kernels tend to zero at the Earth's surface and the CMB.

The prominent regional geoid high in the western Pacific is explained by upper mantle slabs [Hager, 1984], and it is now widely agreed upon that the major geoid lows correspond to the history of subduction and lower mantle slabs [Richards and Engebretson, 1992; Ricard et al., 1993a].

Figure 3. (a) Measured, nonhydrostatic geoid obtained from satellite-only gravity model GL04S1 [Förste et al., 2006; Nakiboglu, 1982]. (b-d) Synthetic geoids for MCMs M1-M3 with different values of core heating $(\mathrm{CH})$, which are given in percent to indicate the core contribution to the total mantle energy budget. The viscosity structure is $\eta_{L I}=100 \cdot 10^{21}, \eta_{A S}=1 \cdot 10^{21}$, and $\eta_{L M}$ $\eta_{L M}=100 \cdot 10^{21}$, as shown in Figure 2. The correlation up to spherical harmonic degree 20 is given on the right of each modeled geoid. Generally, there is good agreement between the modeled and the observed geoid undulations in terms of shape as well as maximum positive and negative amplitudes (observed maximum amplitudes, $-121 / 107 \mathrm{~m} ; 5 \% \mathrm{CH},-114 / 77 \mathrm{~m} ; 20 \% \mathrm{CH}$, $-115 / 77 \mathrm{~m}$; and $40 \% \mathrm{CH},-133 / 99 \mathrm{~m}$ ). Increasing core heating results in growing geoid highs as can be seen, for example, in the southern Indian Ocean. This is due to the additional buoyancy associated with hot upwellings. Some misfits can, however, be found, as for example, the overestimated geoid low in eastern Asia. As the density structure of $\mathrm{M} 1-\mathrm{M} 3$ is mainly controlled by the assimilated plate motion history used as boundary condition for mantle flow, it is possible that these differences arise from uncertainties in the applied subduction history.
[21] The density structure from our MCMs confirms this interpretation. The modeled geoids (Figures $3 b-3 d$ ) for varying core heating $(\mathrm{CH})$ agree well with the observed geoid undulations in terms of shape as well as maximum positive and negative amplitudes (observed max. amplitudes: $-121 / 107 \mathrm{~m} ; 5 \% \mathrm{CH}:-114 / 77 \mathrm{~m} ; 20 \% \mathrm{CH}$ : $-115 / 77 \mathrm{~m} ; 40 \% \mathrm{CH}:-133 / 99 \mathrm{~m})$ since their density structure is controlled mainly by the assim-
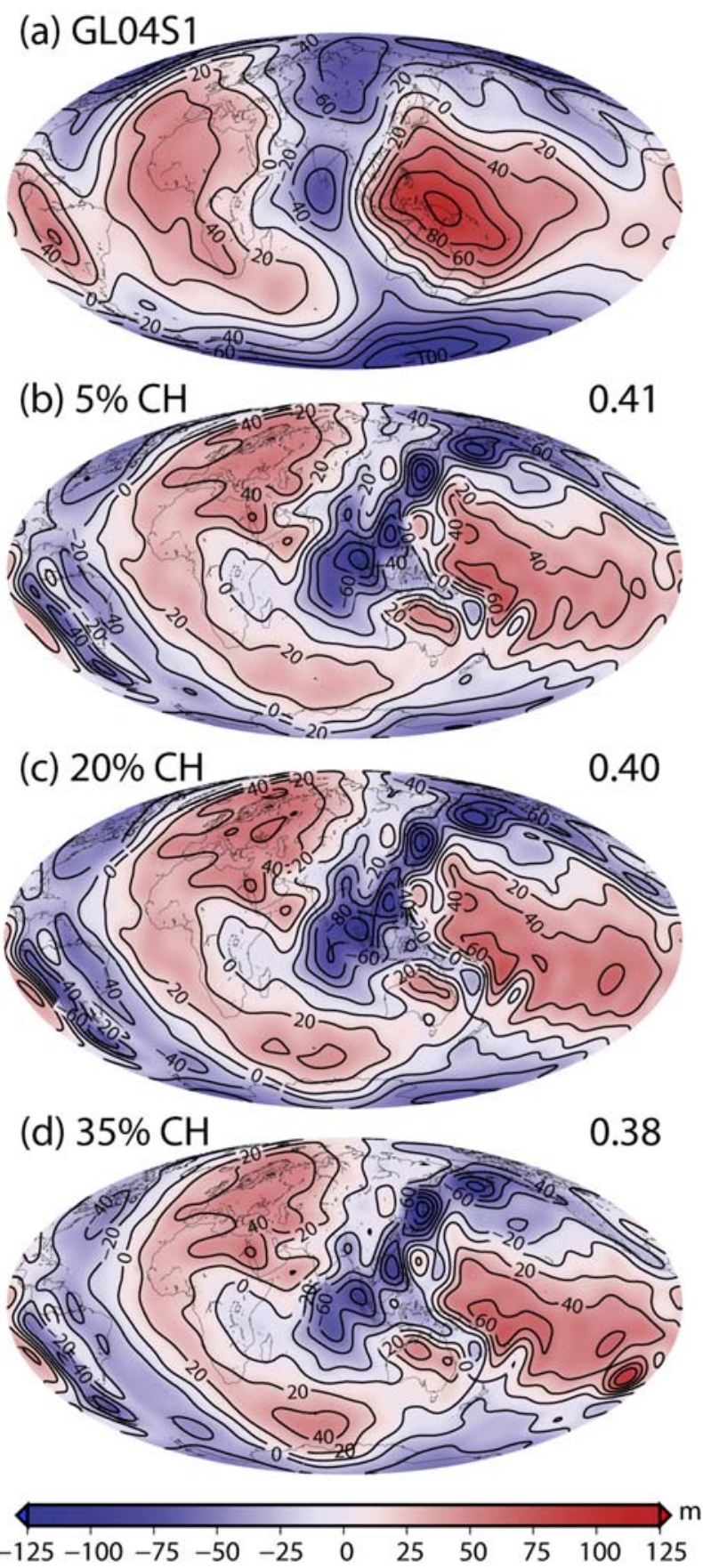


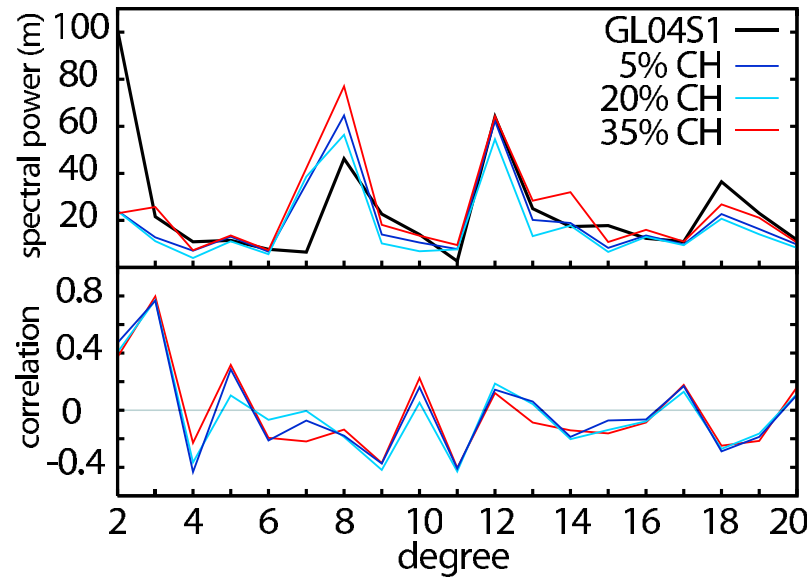

Figure 4. (top) Spectral amplitude of synthetic geoids from MCMs M1-M3 with different amounts of core heating (colored lines) together with the measured geoid GL04S1 (black) [Förste et al., 2006; Nakiboglu, 1982]. Note that the amplitude of degree two does not change much with core heating. (bottom) Correlation of our synthetic with the observed geoid as a function of spherical harmonic degree. From the high correlation of the lowest degrees, agreement in the large-scale pattern of modeled and observed geoids is evident.

ilated plate motion history. Models with higher core heat flux have a larger amplitude of their geoid highs, as expected, due to the additional buoyancy associated with hot upwellings.

[22] Apart from the generally good agreement, there are important differences between modeled and observed geoids. For example, all models produce a geoid low in eastern Asia of much larger amplitude than observed, and there is also a minor geoid low over central Africa. It is likely that these differences arise from uncertainties in the assumed subduction history, as we will see later on.

[23] Figure 4 shows the spectral power of the observed and modeled geoids, and the correlation between models and observation at each spherical harmonic degree. The correlation per degree $C(l)$ and the total correlation $C^{L}$ are computed as follows from the spherical harmonic coefficients of the measured and the computed geoid $\left(N_{l m, M}\right.$ and $N_{l m, C}$, respectively) [Hager, 1984; Ricard et al., 1993a]:

$$
\begin{aligned}
C(l) & =\frac{\sum_{m=-l}^{l} N_{l m, M} N_{l m, C}}{\sqrt{\left(\sum_{m=-l}^{l} N_{l m, M}^{2}\right)\left(\sum_{m=-l}^{l} N_{l m, C}^{2}\right)}} \\
C^{L} & =\frac{\sum_{l=0}^{L} \sum_{m=-l}^{l} N_{l m, M} N_{l m, C}}{\sqrt{\left(\sum_{l=0}^{L} \sum_{m=-l}^{l} N_{l m, M}^{2}\right)\left(\sum_{l=0}^{L} \sum_{m=-l}^{l} N_{l m, C}^{2}\right)}} .
\end{aligned}
$$

[24] The spectral power per degree agrees well between observed and modeled geoids, except for degree two, which is too small in all MCMs, and degrees seven and eight, which are too large.

[25] Agreement in the large-scale pattern of modeled and observed geoids is evident from the high correlation at the lowest spherical harmonic degrees, mainly degrees two and three. There is anticorrelation at degree four, but the spectral amplitude of this degree is small. At higher spectral degrees the correlation varies considerably. For example, degrees nine, eleven and eighteen are strongly anticorrelated with the observed geoid (up to $-40 \%$ ), while degrees ten, twelve, seventeen and twenty correlate positively, up to $35 \%$.

\subsection{True Polar Wander}

[26] The tendency of a rotating body to turn around its largest principal axis of inertia in order to minimize energy is expressed in the conservation of torque, which is described in a rotating reference system tied to the angular velocity $\boldsymbol{\omega}$ of the Earth. No external torques and no internal angular momenta are assumed; the resulting equation of motion for the Earth's pole is called the Liouville equation:

$$
\frac{d}{d t} \mathbf{H}+\boldsymbol{\omega} \times \mathbf{H}=0,
$$

where the angular momentum $\mathbf{H}$ can be written in terms of the full inertia tensor $\mathbf{I}(t)$ :

$$
\mathbf{H}(t)=\mathbf{I}(t) \cdot \boldsymbol{\omega} .
$$

I(t) may be decomposed into three parts, noting $\delta_{i j}$ the Kronecker symbol:

$$
I_{i j}=I_{0} \delta_{i j}+I_{i j}^{c}+\Delta I_{i j} .
$$

The first term $I_{0}=0.33 M R_{e}^{2}$ is the inertia tensor of a spherical nonrotating Earth with a mass $M$ and a radius $R_{e}$. The second term $I_{i j}^{c}$ is due to the centrifugal potential and represents the rotational bulge, which controls the rate of polar motion. The last term $\Delta I_{i j}$ describes changes in the inertia due to internal mass redistributions, that is the excitation function [Ricard et al., 1993b]. This forcing term relates linearly to the spherical harmonic coefficients of degree two of the gravitational potential (the whole set of coefficients of the gravitational potential, nondimensionalized by a scaling factor of $\frac{M \cdot G}{R_{e}}$, are usually called the "Stokes 
coefficients"). This relation is called McCullagh's formula [e.g., Munk and McDonald, 1960]:

$$
\begin{aligned}
& \Delta I_{11}=M R_{e}^{2}\left(\frac{1}{3} \sqrt{5} C_{20}-2 \sqrt{\frac{5}{12}} C_{22}\right) \\
& \Delta I_{22}=M R_{e}^{2}\left(\frac{1}{3} \sqrt{5} C_{20}+2 \sqrt{\frac{5}{12}} C_{22}\right) \\
& \Delta I_{33}=-M R_{e}^{2} \frac{2}{3} \sqrt{5} C_{20} \\
& \Delta I_{12}=-M R_{e}^{2} 2 \sqrt{\frac{5}{12}} S_{22} \\
& \Delta I_{23}=-M R_{e}^{2} \sqrt{\frac{5}{3}} S_{21} \\
& \Delta I_{13}=-M R_{e}^{2} \sqrt{\frac{5}{3}} C_{21} .
\end{aligned}
$$

[27] The Stokes coefficients are related to the coefficients of the geoid via Brun's formula [e.g., Lambeck, 1988]:

$$
\begin{aligned}
& N_{l m}=\frac{M \cdot G}{R_{e} \cdot g\left(R_{e}\right)} C_{l m}, \quad m \geq 0 \\
& N_{l m}=\frac{M \cdot G}{R_{e} \cdot g\left(R_{e}\right)} S_{l m}, \quad m<0 .
\end{aligned}
$$

The centrifugal part $I_{i j}^{c}$ describes the time-dependent behavior of the equatorial bulge and thus is equal to the convolution of the tidal Love number $k^{T}(t)$ with the time history of the changes in the centrifugal potential:

$$
I_{i j}^{c}(t)=\frac{R_{e}^{5}}{3 G} k^{T}(t) *\left[\omega_{i}(t) \omega_{j}(t)-\frac{1}{3} \omega^{2}(t) \delta_{i j}\right]
$$

where $G$ is the gravity constant and the star represents the time convolution. The tidal Love number $k^{T}(t)$ describes the viscoelastic relaxation of the Earth's rotational bulge. For the long time scales associated with mantle flow it is referred to as the quasi fluid Love number and decomposes into the relaxation time of the bulge $T_{1}$ and the timeindependent fluid Love number of degree two $k^{T}$ [see Ricard et al., 1992, 1993b; Greff-Lefftz, 2004]. The MCM viscosity profile (shown in Figure 2) combined with the density and rigidity structure of PREM [Dziewonski and Anderson, 1981] yields $T_{1}=49.847 \mathrm{ka}$ and $k^{T}=0.9339$ for our models. The solution of the Liouville equation is carried out backward in time with the initial position of the pole being at the North Pole.

[28] In Figure 5a, we track the polar motion induced in the three MCMs for the past $100 \mathrm{Myr}$. Dark blue denotes M1 with 5\% CH, light blue denotes M2 with $20 \% \mathrm{CH}$, and red shows the TPW for M3 with 35\% CH. The TPW path is similar in all models. Going back in time, we see that the paths start at the present position of the North Pole, travel southeast up to about $40 \mathrm{Ma}$, and then change direction by moving south-southwest until $100 \mathrm{Ma}$. Note that the TPW amplitude does not exceed $20^{\circ}$ in any of the models $\left(19.71^{\circ}\right.$ for M1, $16.35^{\circ}$ for $\mathrm{M} 2$ and $18.69^{\circ}$ for M3).

[29] The largest principle axis of inertia (PIA) for each time step and model is shown in Figure 5b, on the same color scale as Figure 5a. Again there is little difference between the models with high and low core heat flux. Starting from the present north pole the PIAs move northeast up to about $20 \mathrm{Ma}$, and southwest for prior times. In M2 and M3 the PIAs lie on the Southern Hemisphere for the earliest time steps, and are depicted with opaque circles.

[30] The paleomagnetically interesting rate of TPW for our models is shown in Figure 5c together with a paleomagnetic bound $\left(0.45^{\circ} \mathrm{Myr}^{-1}\right)$ over the past 100 Myr taken from Besse and Courtillot [2002], although we note that this represents an upper bound that should be lowered to account for the inherent motion of mantle hot spots [Tarduno, 2007; Tarduno et al., 2009]. The most rapid motion of up to $0.425^{\circ} \mathrm{Myr}^{-1}$ occurs in the last $20 \mathrm{Myr}$, where models with stronger core heating (M2 and M3) are marginally faster than M1. At earlier times the motion slows to less than $0.3^{\circ} \mathrm{Myr}^{-1}$ in all models.

[31] To better illuminate the core heating effect on the mantle density structure and induced polar motion we track the temporal evolution of largescale density heterogeneity in our models (M1M3) in Figure 6. There, the spectral amplitude of spherical harmonic degree two is contoured as a function of depth and time together with the geoid kernel of degree two. The most noticeable feature in Figure 6 is the strong correspondence between degree two heterogeneity at the CMB and increasing core heat flux, which illustrates the influence of bottom heating on deep mantle mass heterogeneity (plumes) rather well. In M1 the amplitude of degree two in the lowermost $500 \mathrm{~km}$ amounts to $1.0 \mathrm{~kg} \mathrm{~m}^{-3}$ over the last $100 \mathrm{Myr}$. But it is closer to $3.0 \mathrm{~kg} \mathrm{~m}^{-3}$ in $\mathrm{M} 2$ and exceeds $4.0 \mathrm{~kg} \mathrm{~m}^{-3}$ in M3. However, we noted before that the geoid kernel acts as weighting function for the gravitational effects of density anomalies, and that the kernel approaches zero at the CMB due to isostatic compensation. Thus, the strong amplitude of degree two heterogeneity near the CMB is ineffective 

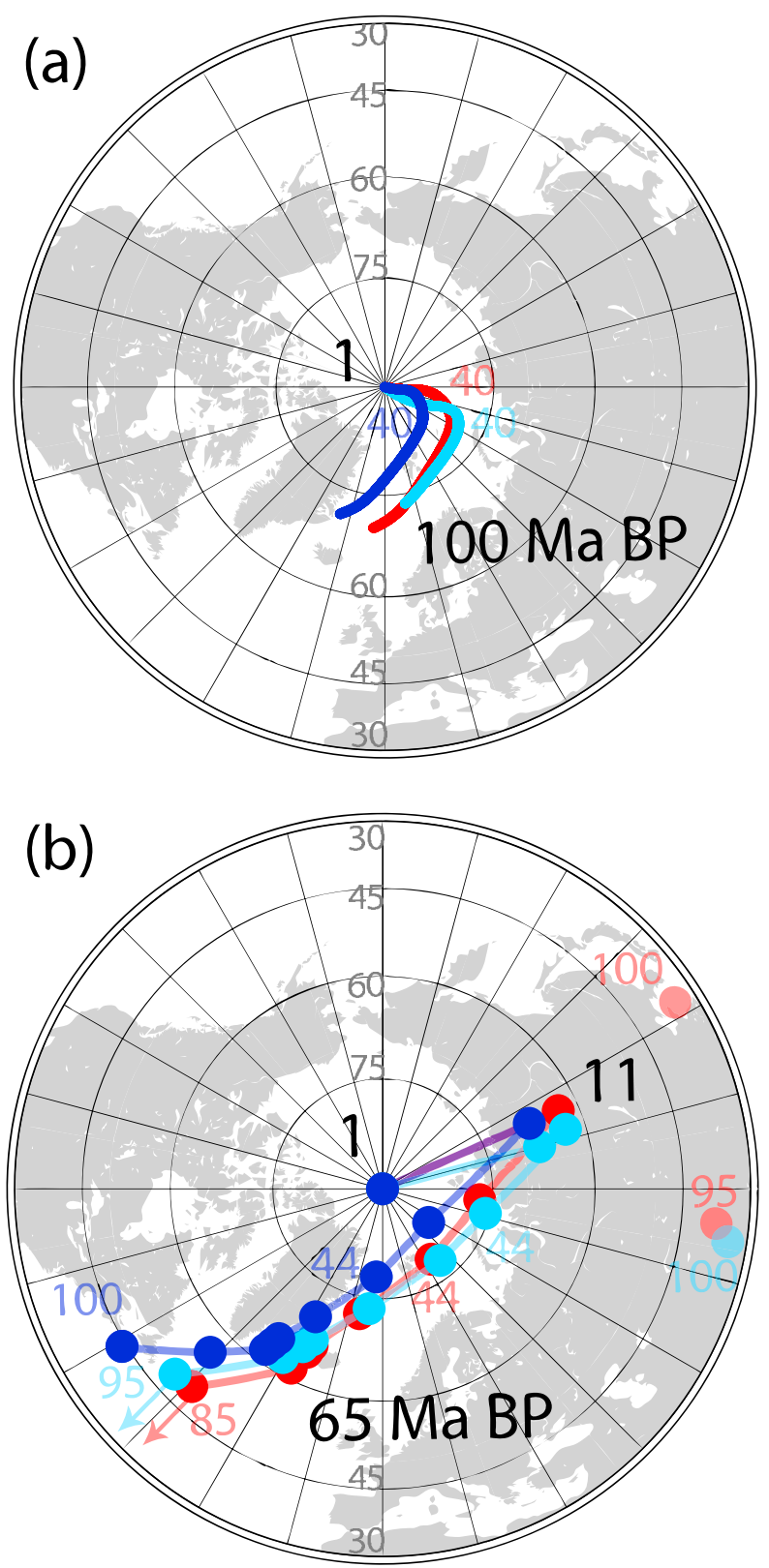

\section{(c) speed ( $\% \mathrm{Ma})$}

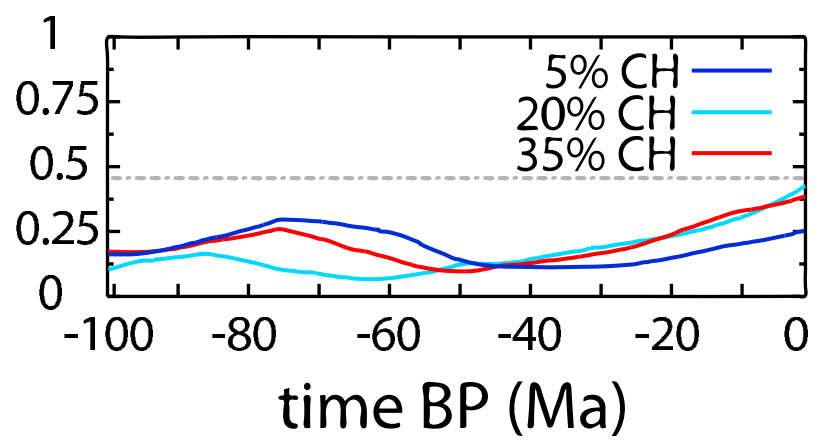

in changing the spectral amplitude of the geoid (Figure 4) and the rotational behavior (Figure 5a) in a significant way.

\section{Discussion}

\subsection{Rotational Stability}

[32] Arguably, the most important result of our study is the rotational stability of MCMs in the presence of strong core heating. Apart from the isochemical, pyrolitic nature of the models, we have made three basic assumptions on character and temporal variability of the MCM density structure: (1) a large-scale mantle flow related to past plate motion, (2) a radial viscosity profile in agreement with postglacial rebound and geoid observations, and (3) a significant contribution to the MCM energy budget from the lower thermal boundary layer, as large as $9-12 \mathrm{TW}$. The first two assumptions are widely agreed upon by geodynamicists, and the rotational stability of geodynamic mantle models constructed under this premise has been verified explicitly [Ricard et al., 1993a; Richards et al., 1997].

[33] The third assumption instead represents a considerable departure from traditional views of large-scale mantle dynamics and the partitioning of buoyancy forces from the upper and lower thermal boundary layer, although it is promoted by a variety of geodynamic considerations and by a range of seismological and mineral physics studies.

Figure 5. (a) Synthetic polar wander paths in the last 100 Myr computed for MCMs M1-M3 with different core heating. (b) Positional variation of the largest principal axis of inertia in the last 100 Myr for M1-M3. Note that opaque circles are used to indicate a change in the axis of principal inertia, which occurs in an early stage of models M2 and M3. (c) Speed of polar wander together with empirically deduced maximum speed [Besse and Courtillot, 2002] (gray dashed line). Despite varying core heating the TPW path is similar in all models: they start at the North Pole, travel southeast up to about $40 \mathrm{Ma}$, and then change direction by moving south-southwest until $100 \mathrm{Ma}$. The TPW amplitude does not exceed $20^{\circ}$ in any of the models $\left(19.71^{\circ}\right.$ for $\mathrm{M} 1$, $16.35^{\circ}$ for $\mathrm{M} 2$, and $18.69^{\circ}$ for M3). The PIA shows little difference between the models as well and changes its direction earlier, at $20 \mathrm{Ma}$. The slow motion of the pole in comparison to the PIA is due to the high viscosity of the lower mantle $\left(10^{23} \mathrm{~Pa} \mathrm{~s}\right)$ in our models, which results in small TPW speeds shown in Figure 5c. All three models are consistent with the paleomagnetic bound of $0.45^{\circ} \mathrm{Myr}^{-1}$ over the last $100 \mathrm{Myr}$. 
For example, a substantial core heat loss is consistent with tomographic inferences of strong lower mantle plumes [Nolet et al., 2006], and with seismological constraints for a high CMB temperature $(3950 \pm 200 \mathrm{~K})$ deduced from inverse scattering of core-reflected shear waves $(\mathrm{ScS})$ [ van der Hilst et al., 2007]. Moreover, high-pressure experi-

(a) $5 \% \mathrm{CH}$

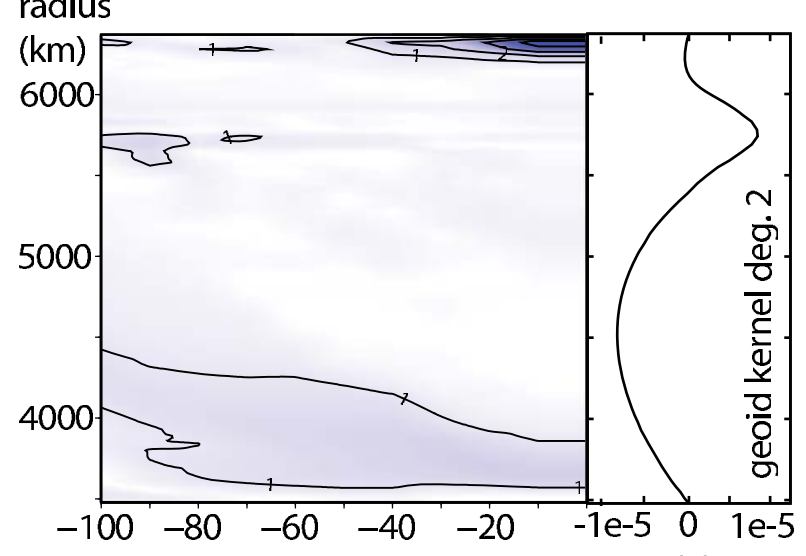

(b) $20 \% \mathrm{CH}$

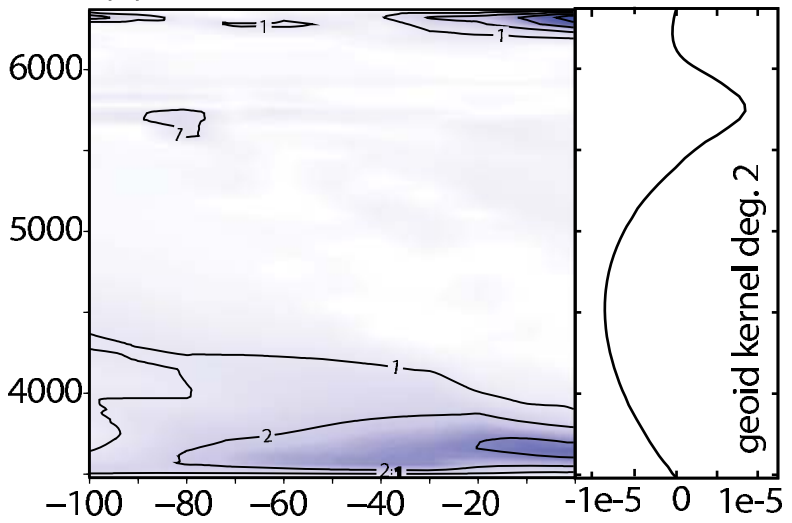

(c) $35 \% \mathrm{CH}$

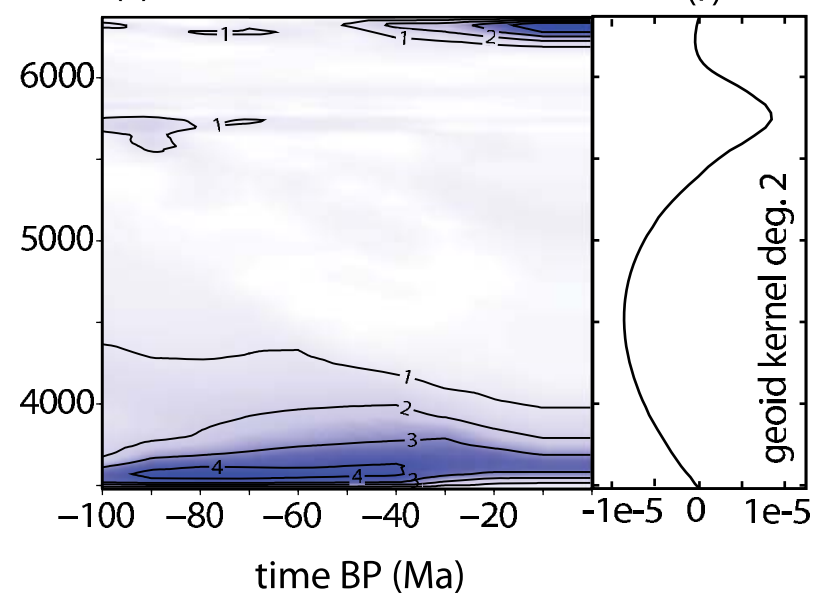



ments on the melting temperature of iron alloys and first-principle calculations on the elastic parameters and melting curve of iron under core conditions also support the notion of strong bottom heating in the mantle, by pointing to an elevated CMB temperature $(4000 \pm 200 \mathrm{~K})$ and a correspondingly high core heat flux [Boehler, 2000; Steinle-Neumann et al., 2001; Alfè et al., 2002].

[34] The small displacement of the rotation axis in our MCMs can be seen from Figure 5 where it is evident that differences in core heat flux do not translate into significantly different pole paths: in fact, direction, amplitude and speed of the modeled TPW remains similar among the MCMs. For example, TPW rate and amplitude (modeled at $<0.425^{\circ} \mathrm{Myr}^{-1}$ and $19.71^{\circ}$, respectively) stay within the paleomagnetic bounds $\left(0.5^{\circ} \mathrm{Myr}^{-1}\right.$ and total displacement of the rotational axis of $<15-20^{\circ}$ in $100 \mathrm{Myr}$ ) suggested by Besse and Courtillot [2002]. We note that the estimate by Besse and Courtillot [2002] can be viewed as an upper bound on polar motion as they are paleomagnetic data viewed in a fixed hot spot reference frame. There is growing acceptance now that hot spots move in the mantle and hence, a part of the polar motion, albeit small, is related to hot spot motion [Tarduno, 2007; Tarduno et al., 2009].

[35] The result is not entirely unexpected. Several studies have concluded that as lower mantle viscosity is raised from $10^{22} \mathrm{~Pa}$ s to $10^{23} \mathrm{~Pa} \mathrm{~s}$, TPW drops to $<0.5^{\circ} \mathrm{Myr}^{-1}$ due to the retarding effect of the rotational bulge [Ricard et al., 1992, 1993b; Greff-Lefftz, 2004; Mitrovica et al., 2005; Tsai and Stevenson, 2007]. Our models confirm this by showing that the spin axis follows the motion of the largest principal axis of inertia rather slowly. Thus any short-term variations in the inertia tensor due to upwelling plumes are effectively damped and translate into minor changes of the TPW path.

Figure 6. (a-c) Spectral amplitude of spherical harmonic degree two of the computed density structures M1-M3 at each depth and time step backward in time. $(d-f)$ Geoid kernel of degree two. From Figures $6 a-6 f$ core heating increases, which mainly affects deep mantle mass anomalies (plumes) in the vicinity at the CMB. As noted in section 3 the geoid kernels act as weighting functions for the gravitational effects of density anomalies. As the kernels approach zero at the $\mathrm{CMB}$, the strong amplitude of degree two heterogeneity near the $\mathrm{CMB}$ is ineffective in changing the spectral amplitude of the geoid (Figure 4) and the rotational behavior (Figure 5a) in a significant way. 


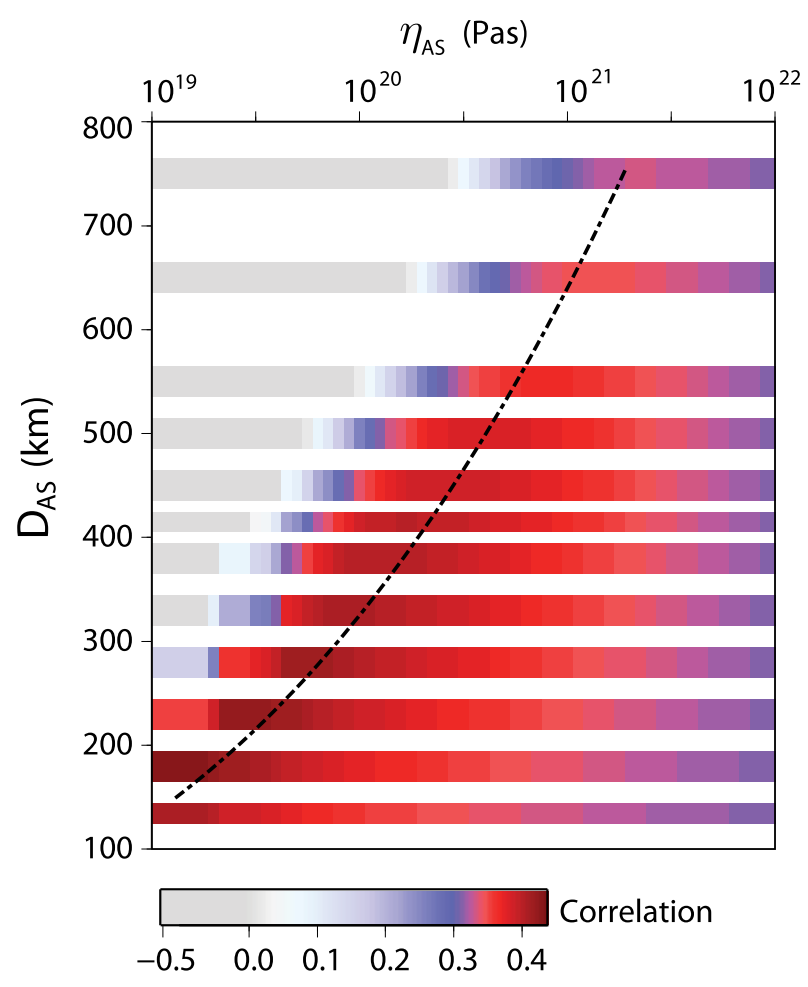

Figure 7. Correlation of the synthetic and measured geoid for different values of the viscosity and thickness of the asthenosphere. The inverse trade-off in asthenosphere thickness and viscosity reduction found here is consistent with the inferences from postglacial rebound (black dashed line) (Paulson and Richards, submitted manuscript, 2009).

[36] In this context, it is worth noting that we apply the same viscosity profile in the computation of the MCM density structure and its associated TPW. Importantly, upon lowering the deep mantle viscosity of our models substantially, we observe that considerable differences arise between the MCMs and seismically observed mantle heterogeneity. Put differently, Mesozoic and Cenozoic slabs in our MCMs would approach mantle depth levels where they are not imaged seismically if we were to adopt lower viscosities than $10^{23} \mathrm{~Pa}$ s for the deep mantle [Schuberth et al., 2009b]. This observation lends independent support for our choice of a substantial increase in lower mantle viscosity. Equally relevant to the rotational stability of our models is the fact that core heating influences the MCM density distribution primarily in the vicinity of the $\mathrm{CMB}$ and the lowermost mantle, as can be seen in Figure 6. This limits their impact on the inertia tensor, because the geoid kernels approach zero in the lowermost mantle. The reason that we can keep the lower mantle viscosity the same for models with varying amounts of core heat flow is that the mean temper- atures (i.e., the model geotherms) are almost identical outside the thermal boundary layer; that is, the lowermost $100 \mathrm{~km}$ of our models. Thus, increased core heating does not imply a weaker lower mantle.

\subsection{Geoid}

[37] The high correlation between observed and modeled geoid agrees with earlier findings which demonstrate that the observed geoid can be explained rather well from mantle density structures related to past subduction [Ricard et al., 1993a; Steinberger, 2000]. The result, however, must be qualified as we have ignored effects of lateral viscosity variations [Zhong and Davies, 1999], together with the effects associated with uncertainties in the radial mantle viscosity profile. Lateral viscosity variations arguably are most important in the lithosphere, where they generate shear localization and plate like behavior through temperature-dependent viscosities and plastic yielding [Tackley, 2000; Richards et al., 2001], although a combination of tectonic and mantle convection modeling appears effective in modeling the complexities of plate boundaries [Iaffaldano et al., 2006; Iaffaldano and Bunge, 2008, 2009].

[38] The values for our choice of the asthenosphere viscosity $\left(10^{21} \mathrm{~Pa} \mathrm{~s}\right)$ and its effective thickness $(500 \mathrm{~km})$ in particular are poorly known. To probe the sensitivity of our results to variations in the viscosity profile, we have computed a range of geoids from $\mathrm{M} 3$, the MCM with $35 \% \mathrm{CH}$. In doing so we left the mass distribution of the model unchanged but have assumed different values for the asthenosphere viscosity and thickness. The model density distribution can be kept the same, as MCMs with the same lower mantle viscosity differ only slightly in terms of their overall density anomalies. This eliminates the need for rerunning the models for each individual viscosity profile used.

[39] Figure 7 shows the correlation between observed and modeled geoid. The viscosity of the lithosphere and lower mantle are kept fixed in all cases $\left(\eta=10^{23} \mathrm{~Pa} \mathrm{~s}\right)$, while the viscosity of the asthenosphere and its thickness $\left(\eta_{A S}\right.$ and $D_{A S}$, respectively) are varied systematically. We find high correlation (shown in red in Figure 7) for several configurations, all of which fall on a line representing the dependence of $\eta_{A S}$ on $D_{A S}^{3} \cdot$ const. This is in good agreement with a recent sensitivity analysis of postglacial rebound data performed by A. Paulson and M. Richards (On the resolution of radial viscosity structure in modeling long-wavelength postglacial rebound data, submitted to Geophysical 
Journal International, 2009), and suggests that our results would be left unchanged if we assumed a thinner and less viscous asthenosphere.

[40] Our assumption of a purely thermal origin of MCM heterogeneity contrasts with geodynamic studies on mantle flow with compositional variations [e.g., Kellogg et al., 1999; Tackley, 2000; Hansen and Yuen, 2000; Montague and Kellogg, 2000; Gurnis et al., 2000; Forte and Mitrovica, 2001; Stegman et al., 2002; McNamara and Zhong, 2004; Farnetani and Samuel, 2005] and with recent interpretations of seismic tomography arguing for substantial thermochemical components of deep mantle heterogeneity [Masters et al., 2000; Ishii and Tromp, 1999; Trampert et al., 2004]. While we cannot preclude the existence of chemical variations in the mantle, we note, however, that a thermal interpretation of lower mantle seismic velocity anomalies is supported by recent joint inversions of seismic data, free-air gravity, dynamic topography and excess ellipticity of the CMB [Simmons et al., 2007, 2009], and that strong lower mantle thermal variations agree with tomographic studies showing a depth-wise increase in heterogeneity strength of low seismic velocity anomalies [Boschi and Dziewonski, 1999; Romanowicz and Gung, 2002; Montelli et al., 2004].

\subsection{Gravity Data and the Potential to Distinguish Between Competing Plate Reconstructions?}

[41] In section 3.1 we noted misfits between the observed and modeled geoid for higher spherical harmonic degrees. One intriguing possibility to explain these misfits; that is, the low to negative correlation for spherical harmonic degrees $>3$, must certainly be sought in the assimilated subduction history of our models. Our choice for past plate motion, as pointed out before, is the widely adopted model of Lithgow-Bertelloni and Richards [1998]. But alternative reconstructions, such as the recent global model of Müller et al. [2008], suggest substantial differences in the implied mantle density structure and its temporal evolution. This is illustrated in Figure 8, where we compare the models of Lithgow-Bertelloni and Richards [1998] and Müller et al. [2008] at four different points in time. The left side shows the reconstruction from Lithgow-Bertelloni and Richards [1998] with black lines outlining the plate boundaries and arrows indicating the direction and velocity of each plate's motion. The right side shows the plate configuration from Müller et al. [2008] with ridges indicated in white and subduction zones in blacks. The age of the oceanic lithosphere is represented in color together with the position of the continents at each time.

[42] A likely example of plate motion related uncertainties in the modeled geoid is our strong overestimation of the Western Pacific geoid low. While the reconstructions by Müller et al. [2008] suggest the presence of a mid-ocean ridge, and thus the subduction of very young ocean floor under Eastern Asia as recent as $70 \mathrm{Ma}$, much older ocean floor is assumed to lie offshore this region in the model of Lithgow-Bertelloni and Richards [1998]. The older but perhaps erroneous age of subducted material implicit in the model of Lithgow-Bertelloni and Richards [1998] would provide a straightforward explanation of why the geoid low modeled from our MCMs is stronger in this region than observed. Equally prominent is the misfit between model and observation in the shape of the African geoid high. The likely cause for this is the substantially more southern location (about $20^{\circ}$ ) of the Africa/Eurasia plate boundary and the assumed subduction polarity in the model of Lithgow-Bertelloni and Richards [1998] relative to the choice of Müller et al. [2008]. Although it is too early to comment in greater detail, further work should be directed at these intriguing differences and geodynamic modelers should use updated plate reconstructions once they become publicly available.

\section{Conclusions}

[43] We have investigated the effects of strongly core heated mantle flow on the stability of the Earth's rotation axis, finding that a large core heat flow of up to $12 \mathrm{TW}$ and strong hot buoyant upwelling plumes with thermal anomalies on the order of $+1000-1500 \mathrm{~K}$ can be reconciled with the observed stability of the Earth's spin axis. The modeled TPW paths agree with the paleomagnetic data in terms of amplitude and speed, the main reason being the lower mantle viscosity in our models with a value of $10^{23} \mathrm{~Pa}$ s. Timeevolving density variations of the Earth for the past $100 \mathrm{Myr}$ are predicted from mantle circulation modeling, which we combined with models of mantle mineralogy to map thermal into corresponding density heterogeneity in a thermodynamically self-consistent way. Geoids and polar wander paths are computed using the same viscosity profile applied in the MCMs. The good correlation of the predicted depth location of downwelling slabs in our MCMs with structure imaged by tomography lends independent support for our viscosity profile. A high numerical resolution of 

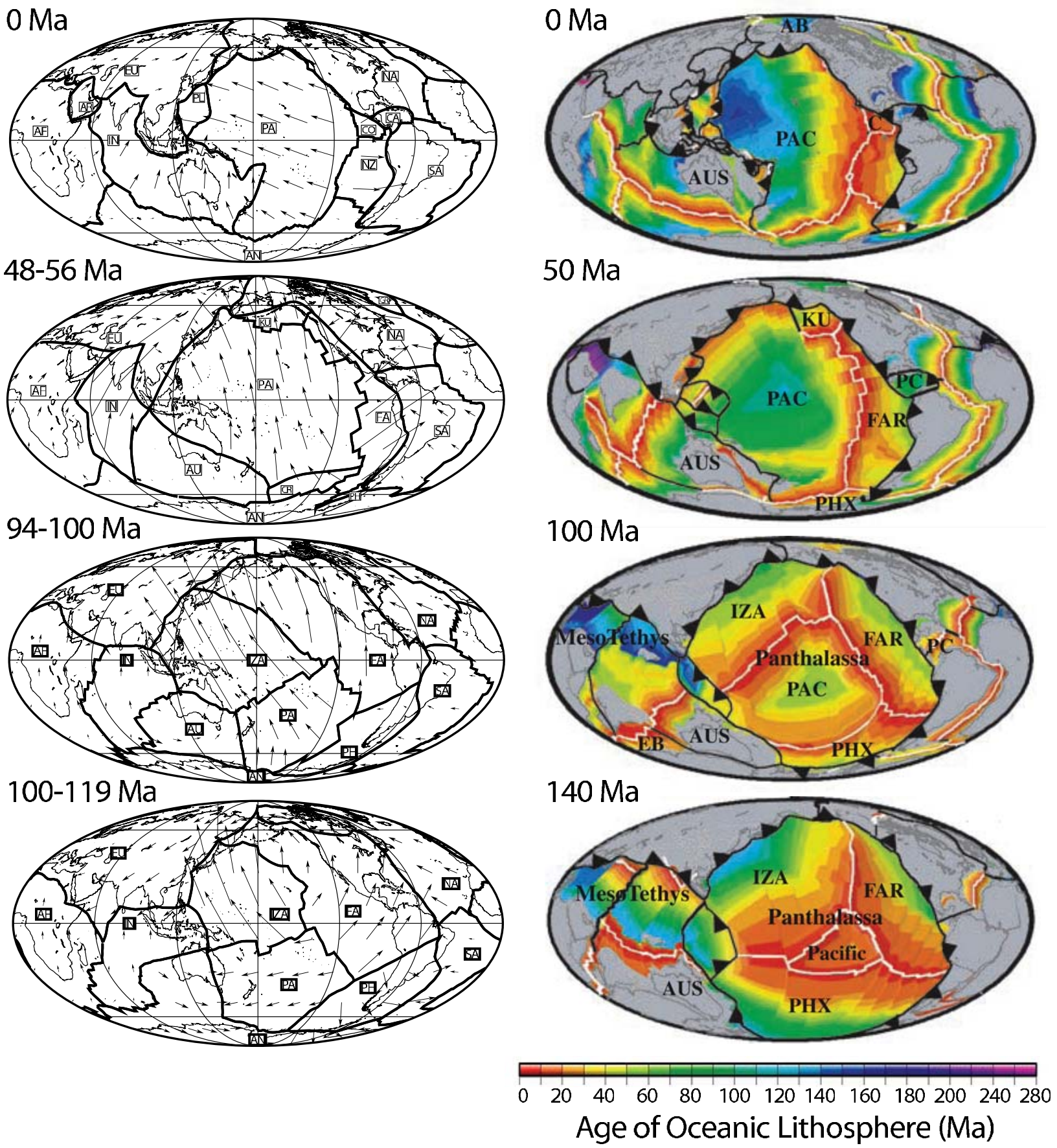

Figure 8. Comparison of plate reconstructions. (left) Plate configurations (black lines) and velocities (arrows) from Lithgow-Bertelloni and Richards [1998] used as boundary conditions in our MCMs. (right) Recent reconstructions from Müller et al. [2008]. Here black and white lines indicate subduction zones and ridges, respectively, and colors illustrate the age of the oceanic lithosphere. Substantial differences between the reconstructions are visible for periods earlier than $70 \mathrm{Ma}$ : While the reconstructions by Müller et al. [2008] suggest the presence of a mid-oceanic ridge in the Pacific at $70 \mathrm{Ma}$, for instance, much older ocean floor is assumed in this region in the model of LithgowBertelloni and Richards [1998]. Another example of the discrepancies is the location of the Africa/Eurasia plate boundary, which lies about $20^{\circ}$ south in the model of Lithgow-Bertelloni and Richards [1998] relative to the choice of Müller et al. [2008]. 
around 80 million finite elements allows us to explore vigorous mantle flow at Earth-like Rayleigh number $\left(10^{9}\right)$ so that modeled thermal variations are consistent with the underlying mineralogy.

[44] Our modeled geoids correlate well with the observed nonhydrostatic geoid at the longest wavelengths. Importantly, it is likely that intermediate wavelength misfits arise from uncertainties in the plate reconstructions, suggesting the use of gravity data to distinguish between competing plate reconstruction models.

\section{Acknowledgments}

[45] Katrin Schaber would like to thank Marianne Greff-Lefftz and Jean Besse for their advice and the opportunity to do research at the IPGP. The authors thank Jerry Mitrovica, Jon Mound, and an anonymous reviewer for their detailed and constructive comments that helped to improve the manuscript. The mantle circulation calculations were partly carried out on the Leibniz-Rechenzentrum (LRZ). We thank the staff of the LRZ for their support. Figures 1 and 3 were generated with GMT4.0 [Wessel and Smith, 1991].

\section{References}

Alfè, D., G. D. Price, and M. J. Gillan (2002), Iron under Earth's core conditions: Liquid-state thermodynamics and high-pressure melting curve from ab initio calculations, Phys. Rev. B, 65(16), 165118, doi:10.1103/PhysRevB.65.165118.

Anderson, D. L. (1982), Hotspots, polar wander, Mesozoic convection and the geoid, Nature, 297(5865), 391-393.

Besse, J., and V. Courtillot (1991), Revised and synthetic apparent polar wander paths of the African, Eurasian, North American and Indian plates, and true polar wander since $200 \mathrm{Ma}, J$. Geophys. Res., 96(B3), 4029-4050.

Besse, J., and V. Courtillot (2002), Apparent and true polar wander and the geometry of the geomagnetic field in the last 200 Myrs, J. Geophys. Res., 107(B11), 2300, doi:10.1029/ 2000JB000050.

Boehler, R. (2000), High-pressure experiments and the phase diagram of lower mantle and core materials, Rev. Geophys., 38(2), 221-245.

Boschi, L., and A. M. Dziewonski (1999), High- and lowresolution images of the Earth's mantle: Implications of different approaches to tomographic modeling, J. Geophys. Res., 104(B11), 25,567-25,594.

Buffett, B. A. (2002), Estimates of heat flow in the deep mantle based on the power requirements for the geodynamo, Geophys. Res. Lett., 29(12), 1566, doi:10.1029/2001GL014649.

Bunge, H. P. (2005), Low plume excess temperature and high core heat flux inferred from non-adiabatic geotherms in internally heated mantle circulation models, Phys. Earth Planet. Inter, 153(1-3), 3-10, doi:10.1016/j.pepi.2005.03.017.

Bunge, H.-P., and M. Richards (1996), The origin of large-scale structure in mantle convection: Effects of plate motions and viscosity stratification, Geophys. Res. Lett., 23, 2987-2990.

Bunge, H.-P., M. Richards, and J. Baumgardner (1996), The effect of depth-dependent viscosity on the planform of mantle convection, Nature, 379, 436-438, doi:10.1038/379436a0.
Bunge, H.-P., M. Richards, and J. Baumgardner (1997), A sensitivity study of 3D-spherical mantle convection at 10exp8 Rayleigh number: Effects of depth-dependent viscosity, heating mode and an endothermic phase change, J. Geophys. Res., 102, 11,991-12,007.

Bunge, H.-P., M. Richards, C. Lithgow-Bertelloni, J. Baumgardner, S. Grand, and B. Romanowicz (1998), Time scales and heterogeneous structure in geodynamic Earth models, Science, 280, 91-95, doi:10.1126/science.280.5360.91.

Bunge, H.-P., Y. Ricard, and J. Matas (2001), Non-adiabaticity in mantle convection, Geophys. Res. Lett., 28(5), 879-882.

Bunge, H.-P., M. Richards, and J. Baumgardner (2002), Mantle circulation models with sequential data-assimilation: Inferring present-day mantle structure from plate motion histories, Philos. Trans. R. Soc. A, 360(1800), 2545-2567, doi:10.1098/ rsta.2002.1080.

Coltice, N., B. R. Phillips, H. Bertrand, Y. Ricard, and P. Rey (2007), Global warming of the mantle at the origin of flood basalts over supercontinents, Geology, 35(5), 391-394.

Costin, S. O., and S. L. Butler (2006), Modelling the effects of internal heating in the core and lowermost mantle on the Earth's magnetic history, Phys. Earth Planet. Inter, 157(12), 55-71, doi:10.1016/j.pepi.2006.03.009.

Davies, G. F. (1988), Ocean bathymetry and mantle convection: 1. Large-scale flow and hotspots, J. Geophys. Res., 93(B9), 10,467-10,480.

Dziewonski, A. M., and D. L. Anderson (1981), Preliminary reference Earth model, Phys. Earth Planet. Inter., 25, 297-356, doi:10.1016/0031-9201(81)90046-7.

Farnetani, C. G., and H. Samuel (2005), Beyond the thermal plume paradigm, Geophys. Res. Lett., 32, L07311, doi:10.1029/2005GL022360.

Förste, C., et al. (2006), A mean global gravity field model from the combination of satellite mission and altimetry/ gravimetry data-EIGEN-GL04C, Geophys. Res. Abstr., 8, 03462.

Forte, A. M., and J. X. Mitrovica (2001), Deep-mantle highviscosity flow and thermochemical structure inferred from seismic and geodynamic data, Nature, 410(6832), 1049-1056.

Forte, A. M., J. X. Mitrovica, and R. L. Woodward (1995), Seismic-geodynamic determination of the origin of excess ellipticity of the core-mantle boundary, Geophys. Res. Lett., 22(9), 1013-1016.

Glatzmaier, G. A., and P. H. Roberts (1995), A 3-dimensional self-consistent computer-simulation of a geomagnetic-field reversal, Nature, 377(6546), 203-209, doi:10.1038/377203a0.

Gordon, R. G., and D. M. Jurdy (1986), Cenozoic global plate motions, J. Geophys. Res., 91(B12), 2389-2406.

Greff-Lefftz, M. (2004), Upwelling plumes, superswells and true polar wander, Geophys. J. Int., 159(3), 1125-1137, doi:10.1111/j.1365-246X.2004.02440.x.

Gurnis, M., J. X. Mitrovica, J. Ritsema, and H.-J. van Heijst (2000), Constraining mantle density structure using geological evidence of surface uplift rates: The case of the African Superplume, Geochem. Geophys. Geosyst., 1(7), 1020, doi:10.1029/1999GC000035.

Hager, B. H. (1984), Subducted slabs and the geoid: Constraints on mantle rheology and flow, J. Geophys. Res., 89, 6003-6015, doi:10.1029/JB089iB07p06003.

Hager, B. H., and M. A. Richards (1989), Long-wavelength variations in Earths geoid-Physical models and dynamical implications, Philos. Trans. R. Soc. A, 328(1599), 309-327, doi:10.1098/rsta.1989.0038.

Hall, R. (2002), Cenozoic geological and plate tectonic evolution of SE Asia and the SW Pacific: Computer-based recon- 
structions, model and animations, J. Asian Earth Sci., 20(4), $353-431$.

Hansen, U., and D. A. Yuen (2000), Extended-Boussinesq thermal-chemical convection with moving heat sources and variable viscosity, Earth Planet. Sci. Lett., 176(3-4), 401-411, doi:10.1016/S0012-821X(00)00009-1.

Iaffaldano, G., and H.-P. Bunge (2008), Strong plate coupling along the Nazca-South America convergent margin, Geology, 36(6), 443-446, doi:10.1130/G24489A.1.

Iaffaldano, G., and H.-P. Bunge (2009), Relating rapid platemotion variations to plate-boundary forces in global coupled models of the mantle/lithosphere system: Effects of topography and friction, Tectonophysics, 474(1-2), 393-404, doi:10.1016/j.tecto.2008.10.035.

Iaffaldano, G., H.-P. Bunge, and T. H. Dixon (2006), Feedback between mountain belt growth and plate convergence, Geology, 34(10), 893-896, doi:10.1130/G22661.1.

Irifune, T. (1987), An experimental investigation of the pyroxene garnet transformation in a pyrolite composition and its bearing on the constitution of the mantle, Phys. Earth Planet. Inter., 45(4), 324-336, doi:10.1016/0031-9201(87)90040-9.

Ishii, M., and J. Tromp (1999), Normal-mode and free-air gravity constraints on lateral variations in velocity and density of Earth's mantle, Science, 285(5431), 1231-1236, doi:10.1126/science.285.5431.1231.

Jeanloz, R., and S. Morris (1987), Is the mantle geotherm subadiabatic, Geophys. Res. Lett., 14(4), 335-338.

Kellogg, L. H., B. H. Hager, and R. D. van der Hilst (1999), Compositional stratification in the deep mantle, Science, 283(5409), 1881-1884, doi:10.1126/science.283.5409.1881.

Kuang, W. L., and J. Bloxham (1997), An Earth-like numerical dynamo model, Nature, 389(6649), 371-374, doi:10.1038/ 38712.

Lambeck, K. (1988), Geophysical Geodesy-The Slow Deformations of the Earth, Clarendon, Oxford, U. K.

Lay, T., J. Hernlund, and B. A. Buffett (2008), Core-mantle boundary heat flow, Nat. Geosci., 1(1), 25-32, doi:10.1038/ ngeo.2007.44.

Leng, W., and S. J. Zhong (2008), Controls on plume heat flux and plume excess temperature, J. Geophys. Res., 113, B04408, doi:10.1029/2007JB005155.

Lithgow-Bertelloni, C., and M. A. Richards (1998), The dynamics of Cenozoic and Mesozoic plate motions, Rev. Geophys., 36(1), 27-78.

Masters, G., G. Laske, H. Bolton, and A. M. Dziewonski (2000), The Relative behavior of shear velocity, bulk sound speed, and compressional velocity in the mantle: Implications for chemical and thermal structure, in Earth's Deep InteriorMineral Physics and Tomography From the Atomic to the Global Scale, Geophys. Monogr. Ser., vol. 117, edited by S. Karato et al., pp. 63-87, AGU, Washington D. C.

McNamara, A. K., and S. J. Zhong (2004), Thermochemical structures within a spherical mantle: Superplumes or piles?, J. Geophys. Res., 109(B7), B07402, doi:10.1029/ 2003 JB002847.

McNamara, A. K., and S. Zhong (2005), Thermochemical structures beneath Africa and the Pacific Ocean, Nature, 437, 1136-1139, doi:10.1038/nature04066.

Mitrovica, J. X. (1996), Haskell [1935] revisited, J. Geophys. Res., 101(B1), 555-569.

Mitrovica, J. X., J. Wahr, I. Matsuyama, and A. Paulson (2005), The rotational stability of an ice-age Earth, Geophys. J. Int., 161, 491-506, doi:10.1111/j.1365-246X.2005. 02609.x.
Mittelstaedt, E., and P. J. Tackley (2006), Plume heat flow is much lower than CMB heat flow, Earth Planet. Sci. Lett., 241(1-2), 202-210, doi:10.1016/j.epsl.2005.10.012.

Monnereau, M., and D. A. Yuen (2002), How flat is the lowermantle temperature gradient?, Earth Planet. Sci. Lett., 202(1), 171-183, doi:10.1016/S0012-821X(02)00756-2.

Montague, N. L., and L. H. Kellogg (2000), Numerical models of a dense layer at the base of the mantle and implications for the geodynamics of $\mathrm{D}^{\prime \prime}, J$. Geophys. Res., 105(B5), $11,101-11,114$.

Montelli, R., G. Nolet, F. A. Dahlen, G. Masters, E. R. Engdahl, and S.-H. Hung (2004), Finite-frequency tomography reveals a variety of plumes in the mantle, Science, 303(5656), 338-343, doi:10.1126/science.1092485.

Müller, R. D., M. Sdrolias, C. Gaina, and W. R. Roest (2008), Age, spreading rates, and spreading asymmetry of the world's ocean crust, Geochem. Geophys. Geosyst., 9, Q04006, doi:10.1029/2007GC001743.

Munk, W. H., and G. J. F. McDonald (1960), The Rotation of the Earth, Cambridge Univ. Press, Cambridge, U. K.

Nakiboglu, S. M. (1982), Hydrostatic theory of the Earth and its mechanical implications, Phys. Earth Planet. Inter., 28, 302-311, doi:10.1016/0031-9201(82)90087-5.

Nimmo, F., G. D. Price, J. Brodholt, and D. Gubbins (2004), The influence of potassium on core and geodynamo evolution, Geophys. J. Int., 156(2), 363-376, doi:10.1111/j.1365246X.2003.02157.x.

Nolet, G., S. I. Karato, and R. Montelli (2006), Plume fluxes from seismic tomography, Earth Planet. Sci. Lett., 248, 685-699, doi:10.1016/j.epsl.2006.06.011.

Oeser, J., H. P. Bunge, and M. Mohr (2006), Cluster design in the Earth sciences-Tethys, High Performance Computing And Communications, Lect. Notes Comput. Sci., 4208, 31-40.

Panasyuk, S. V., B. H. Hager, and A. M. Forte (1996), Understanding the effects of mantle compressibility on geoid kernels, Geophys. J. Int., 124(1), 121-133, doi:10.1111/j.1365-246X. 1996.tb06357.x.

Phillips, B. R., and H.-P. Bunge (2005), Heterogeneity and time dependence in 3D spherical mantle convection models with continental drift, Earth Planet. Sci. Lett., 233(1-2), 121-135, doi:10.1016/j.epsl.2005.01.041.

Phillips, B. R., and H.-P. Bunge (2007), Supercontinent cycles disrupted by strong mantle plumes, Geology, 35, 847-850, doi:doi:10.1130/G23686A.1.

Phillips, B. R., H. P. Bunge, and K. Schaber (2009), True polar wander in mantle convection models with multiple, mobile continents, Gondwana Res., 15(3-4), 288-296, doi:10.1016/j.gr.2008.11.007.

Piazzoni, A. S., G. Steinle-Neumann, H.-P. Bunge, and D. Dolejš (2007), A mineralogical model for density and elasticity of the Earth's mantle, Geochem. Geophys. Geosyst., 8, Q11010, doi:10.1029/2007GC001697.

Quere, S., D. Rowley, A. Forte, and R. Moucha (2007), No-net-rotation and Indo-Atlantic hotspot reference frames: Towards a new view of tectonic plate motions and Earth dynamics, Eos Trans. AGU, 88(52), Fall Meet. Suppl., Abstract U34A-03.

Ricard, Y., L. Fleitout, and C. Froidevaux (1984), Geoid heights and lithospheric stresses for a dynamic Earth, Ann. Geophys., 2, 267-285.

Ricard, Y., R. Sabadini, and G. Spada (1992), Isostatic deformations and polar wander induced by redistribution of mass within the Earth, J. Geophys. Res., 97, 14,223-14,236. 
Ricard, Y., M. Richards, C. Lithgow-Bertelloni, and Y. LeStunff (1993a), A geodynamic model of mantle density heterogeneity, J. Geophys. Res., 98(B12), 21,895-21,909.

Ricard, Y., G. Spada, and R. Sabadini (1993b), Polar wandering of a dynamic Earth, Geophys. J. Int., 113(2), 284-298, doi:10.1111/j.1365-246X.1993.tb00888.x.

Richards, M. A., and D. C. Engebretson (1992), Large-scale mantle convection and the history of subduction, Nature, 355(6359), 437-440, doi:10.1038/355437a0.

Richards, M. A., and B. H. Hager (1984), Geoid anomalies in a dynamic Earth, J. Geophys. Res., 89, 5987-6002.

Richards, M. A., Y. Ricard, C. Lithgow-Bertelloni, G. Spada, and R. Sabadini (1997), An explanation of Earth's long-term rotational stability, Science, 275, 372-375.

Richards, M. A., H.-P. Bunge, Y. Ricard, and J. R. Baumgardner (1999), Polar wandering in mantle convection models, Geophys. Res. Lett., 26, 1777-1780, doi:10.1029/1999GL900331.

Richards, M. A., W.-S. Yang, J. R. Baumgardner, and H.-P. Bunge (2001), Role of a low-viscosity zone in stabilizing plate tectonics: Implications for comparative terrestrial planetology, Geochem. Geophys. Geosyst., 2(8), 1026, doi:10.1029/ $2000 \mathrm{GC} 000115$.

Ringwood, A. E. (1975), Composition and Petrology of the Earth's Mantle, McGraw-Hill, New York.

Romanowicz, B., and Y. C. Gung (2002), Superplumes from the core-mantle boundary to the lithosphere: Implications for heat flux, Science, 296, 513-516, doi:10.1126/science. 1069404

Schuberth, B. S. A., H.-P. Bunge, and J. Ritsema (2009a), Tomographic filtering of high-resolution mantle circulation models: Can seismic heterogeneity be explained by temperature alone?, Geochem. Geophys. Geosyst., 10, Q05W03, doi:10.1029/2009GC002401.

Schuberth, B. S. A., H.-P. Bunge, G. Steinle-Neumann, C. Moder, and J. Oeser (2009b), Thermal versus elastic heterogeneity in high-resolution mantle circulation models with pyrolite composition: High plume excess temperatures in the lowermost mantle, Geochem. Geophys. Geosyst., 10, Q01W01, doi:10.1029/2008GC002235.

Simmons, N. A., A. M. Forte, and S. P. Grand (2007), Thermochemical structure and dynamics of the African superplume, Geophys. Res. Lett., 34, L02301, doi:10.1029/ 2006 GL028009.

Simmons, N. A., A. M. Forte, and S. P. Grand (2009), Joint seismic, geodynamic and mineral physical constraints on three-dimensional mantle heterogeneity: Implications for the relative importance of thermal versus compositional heterogeneity, Geophys. J. Int., 177(3), 1284-1304, doi:10.1111/ j.1365-246X.2009.04133.x.

Sleep, N. H. (1990), Hotspots and mantle plumes: Some phenomenology, J. Geophys. Res., 95(B5), 6715-6736.
Sleep, N. H. (2003), Simple features of mantle-wide convection and the interpretation of lower-mantle tomograms, $C$. $R$. Geosci., 335(1), 9-22, doi:10.1016/S1631-0713(03)00008-7.

Stegman, D. R., M. A. Richards, and J. R. Baumgardner (2002), Effects of depth-dependent viscosity and plate motions on maintaining a relatively uniform mid-ocean ridge basalt reservoir in whole mantle flow, J. Geophys. Res., 107(B6), 2116, doi:10.1029/2001JB000192.

Steinberger, B. (2000), Slabs in the lower mantle-Results of dynamic modelling compared with tomographic images and the geoid, Phys. Earth Planet. Inter., 118(3-4), 241-257, doi:10.1016/S0031-9201(99)00172-7.

Steinberger, B., and R. J. O'Connell (1997), Changes of the Earth's rotation axis owing to advection of mantle density heterogeneities, Nature, 387(6629), 169-173.

Steinle-Neumann, G., L. Stixrude, R. E. Cohen, and O. Gulseren (2001), Elasticity of iron at the temperature of the Earth's inner core, Nature, 413(6851), 57-60, doi:10.1038/35092536.

Stixrude, L., and C. Lithgow-Bertelloni (2007), Influence of phase transformations on lateral heterogeneity and dynamics in Earth's mantle, Earth Planet. Sci. Lett., 263, 45-55, doi:10.1016/j.epsl.2007.08.027.

Tackley, P. J. (2000), Mantle convection and plate tectonics: Toward an integrated physical and chemical theory, Science, 288(5473), 2002-2007, doi:10.1126/science.288.5473. 2002.

Tarduno, J. A. (2007), On the motion of Hawaii and other mantle plumes, Chem. Geol., 241(3-4), 234-247, doi:10.1016/j.chemgeo.2007.01.021.

Tarduno, J. A., and A. V. Smirnov (2001), Stability of the Earth with respect to the spin axis for the last 130 million years, Earth Planet. Sci. Lett., 184(2), 549-553.

Tarduno, J., H. P. Bunge, N. Sleep, and U. Hansen (2009), The bent Hawaiian-Emperor hotspot track: Inheriting the mantle wind, Science, 324(5923), 50-53, doi:10.1126/ science. 1161256 .

Trampert, J., F. Deschamps, J. Resovsky, and D. Yuen (2004), Probabilistic tomography maps chemical heterogeneities throughout the lower mantle, Science, 306(5697), 853856, doi:10.1126/science.1101996.

Tsai, V. C., and D. J. Stevenson (2007), Theoretical constraints on true polar wander, J. Geophys. Res., 112, B05415, doi:10.1029/2005JB003923.

van der Hilst, R. D., M. V. de Hoop, P. Wang, S. H. Shim, P. Ma, and L. Tenorio (2007), Seismostratigraphy and thermal structure of Earth's core-mantle boundary region, Science, 315, 1813-1817, doi:10.1126/science.1137867.

Wessel, P., and W. H. F. Smith (1991), Free software helps map and display data, EOS Trans. AGU, 72(441), 441.

Zhong, S. J., and G. F. Davies (1999), Effects of plate and slab viscosities on the geoid, Earth Planet. Sci. Lett., 170(4), 487-496. 